\title{
Sociolinguística, teoria social e padronização linguística
}

\section{Sociolinguistics, social theory and linguistic standardization}

\author{
Marcos Bispo dos Santos \\ Universidade do Estado da Bahia, Alagoinhas, Bahia/Brasil \\ mabispo@uneb.br
}

Resumo: Neste artigo, questiona-se a pertinência e a relevância da sociolinguística variacionista como ciência aplicada na abordagem de questões relativas à padronização linguística no Brasil. Para isso, fez-se uma pesquisa bibliográfica dividida em dois eixos, o linguístico e o sociológico, com o intuito de compreender as bases teóricas da sociolinguística brasileira. No primeiro eixo, buscou-se compreender a natureza da sociolinguística com base nas pesquisas de Labov. No segundo, situou-se o componente propriamente sociológico da sociolinguística no contexto das teorias sociais. A análise evidenciou que a metodologia da pesquisa, no contexto da sociolinguística variacionista, é marcadamente positivista e não se coaduna com os princípios da pesquisa social contemporânea. Verificou-se ainda que a tese da ideologia dominante, elemento central da teoria social da sociolinguística brasileira, além de não exercer influência significativa na metodologia da pesquisa, já foi amplamente questionada e não exerce influência na pesquisa social contemporânea.

Palavras-chave: padronização linguística; sociolinguística variacionista; teoria social.

Abstract: In this article, we discuss the pertinence and relevance of Brazilian variationist sociolinguistics as applied science in the approach of issues related to linguistic standardization. In order to do so, we conducted a bibliographical research divided into two axes, the linguistic one and the sociological one, aiming at understanding the theoretical 
bases of Brazilian sociolinguistics. In the first axis, we discussed the nature of sociolinguistics taking Labov's research as a starting point. Then, we situated the sociological component of sociolinguistics in the context of Social Theories. The analysis showed that in the context of variationist sociolinguistics, the research methodology is markedly positivist and does not conform to the principles of contemporary social research. We also observed that the Dominant Ideology Theory, a central element in the social theory of Brazilian sociolinguistics, not only did not exert significant influence in the methodology of the research works carried out in the area, but also had already been widely questioned in the context of social research and does not present satisfactory answers to the problems it is supposed to explain.

Keywords: linguistic standardization; variacionist sociolinguistics; social theory.

Recebido em 3 de agosto de 2017

Aceito em 3 de outubro de 2017

\section{Introdução}

A sociolinguística variacionista, aquela que tem em Labov seu maior expoente, é hoje a principal referência teórica acerca de questões relativas à variação linguística. Embora essa ciência adote uma metodologia que articula fatores linguísticos e sociais com o objetivo precípuo de explicar a mudança linguística, os resultados das pesquisas orientadas pelo modelo laboviano se tornaram referências para orientar o discurso acadêmico nos debates que envolvem a padronização linguística no Brasil. Diante desse contexto, o problema central discutido neste texto é o seguinte: uma teoria que surge com o propósito de explicar a mudança linguística pode ser usada como fundamentação para reorientar a forma de conceber e implementar as políticas de regulamentação linguística? Com o objetivo de refletir sobre a pertinência da sociolinguística variacionista como ciência aplicada para abordar questões relativas à padronização linguística, dividiu-se o texto em três partes apresentadas a seguir.

Na primeira, confronta-se a sociolinguística com a sociologia da linguagem no que se refere ao tratamento da variação estilística e da 
padronização linguística. Na concepção de Labov, essa é uma distinção fundamental para a definição da natureza da sociolinguística como uma teoria da língua, que não contempla questões políticas amplas relativas a seu funcionamento social. Por outro lado, a abordagem sociológica de Bourdieu apresenta as limitações de uma perspectiva linguística estrita para lidar com processos sociais que envolvem a variação estilística e o funcionamento da língua legítima. Paradoxalmente, na abordagem que chamaremos aqui de sociolinguística aplicada brasileira ${ }^{1}$, mesmo admitindo-se o princípio metodológico da articulação entre língua e sociedade, tem-se defendido a negação de critérios sociais como prioritários na definição do padrão linguístico unificador. Com base no princípio da regularidade interna das variedades linguísticas, propõe que a padronização da língua se dê levando em conta as regras inerentes ao próprio sistema linguístico. Diante disso, uma vez reconhecida a necessidade de um padrão linguístico nacional pelos próprios sociolinguistas aplicados, a alternativa adotada foi buscar a definição de uma norma culta real, extraída da análise da fala de pessoas arbitrariamente definidas como cultas pelos pesquisadores. A partir daí, instaurou-se a distinção entre norma culta, concebida como real, por, supostamente, refletir o uso efetivo e intuitivo do grupo social selecionado, e a norma padrão, vista pelos pesquisadores como idealizada, artificial e abstrata, por não ser a língua natural de nenhum falante. A seção apresenta alguns problemas da solução proposta pelos sociolinguistas aplicados e finaliza com a seguinte questão: uma ciência aplicada que

\footnotetext{
${ }^{1} \mathrm{O}$ uso da expressão sociolinguística aplicada, neste texto, baseia-se na distinção entre antropologia teórica e antropologia aplicada proposta por Bastide (2009), que atribui a esta última o papel de transferir os conhecimentos da primeira à compreensão e à resolução de problemas práticos da vida sociocultural. Assim, a expressão sociolinguística aplicada recobre as discussões de linguistas que se propõem a utilizar conceitos, métodos e resultados das pesquisas sociolinguísticas variacionistas como fundamentos de propostas para reformar as políticas linguísticas e o ensino de língua na educação básica. Esses linguistas compõem um grupo heterogêneo, uma vez que alguns deles são realmente pesquisadores que utilizam os princípios teórico-metodológicos de Labov, como Lucchesi (2015) e Scherre (2005), enquanto outros, que não realizam pesquisas sociolinguísticas propriamente ditas, como Bagno (2003, 2009, 2010), Mattos e Silva (2005), Faraco (2008), por exemplo, voltam-se para discussões sobre a necessidade de aplicar os saberes da sociolinguística teórica a contextos sociais mais amplos que os contemplados nas pesquisas empíricas.
} 
se propõe ao estudo das relações entre língua e sociedade pode excluir deliberadamente de seu campo de interesse a língua institucionalizada e socialmente reconhecida como padrão?

Para responder a essa questão, na segunda parte, discutem-se os fundamentos epistemológicos da sociolinguística, iniciando pela compreensão dos fatores que caracterizam a disciplina no modelo de Labov até sua perspectiva aparentemente interdisciplinar. A análise do caminho percorrido pela disciplina revela a existência de dois eixos que se justapõem na sociolinguística brasileira: o linguístico, de base positivista, e o sociológico, que busca aplicar, de maneira transpositiva, os resultados da pesquisa às políticas de regulamentação linguística, aliando à proposta uma concepção da teoria social clássica conhecida como tese da ideologia dominante. A mera justaposição entre os dois eixos é decorrente de uma separação entre duas atividades que deveriam ser realizadas de maneira harmônica em uma disciplina constituída segundo os princípios da interdisciplinaridade, ou seja, pesquisa e interpretação. Dessa forma, não há uma integração entre os eixos linguístico e sociológico para a constituição da metodologia da pesquisa, que, em razão disso, é ainda marcadamente positivista e orientada para o estudo dos fenômenos puramente linguísticos, enquanto a interpretação se dá com base na tese da ideologia dominante, baseada na versão ortodoxa do marxismo. Nesses termos, a revolução social no campo da regulamentação linguística darse-ia pela aplicação dos conhecimentos científicos às questões sociais, pela via exclusiva da interpretação, uma vez que as questões sociológicas não são consideradas na metodologia de pesquisa.

$\mathrm{Na}$ terceira parte, são discutidos os problemas da teoria social em que se fundamentam as interpretações dos sociolinguistas brasileiros acerca da padronização linguística (LUCCHESI, 2015; FARACO, 2008; ZILLES; FARACO, 2015; MARTINS; VIEIRA; TAVARES, 2014; SCHERRE, 2005; BAGNO, 2003). A tese da ideologia dominante é situada no contexto geral da teoria social para que seja avaliado seu potencial de apresentar explicações pertinentes das relações sociais. A análise evidencia que a teoria social contemporânea se afastou do consenso ortodoxo sobre a teoria social clássica de base marxista, que fundamenta a tese da ideologia dominante, por dois fatores igualmente problemáticos para o estudo da sociedade: o reducionismo econômico e o de classe, ambos estabelecidos pelo reducionismo estrutural. 


\section{A variação estilística e o problema da padronização linguística}

A história do estilo como objeto de estudo da linguística tem início com os trabalhos de Charles Bally no início do século XX. Hoje os fenômenos abordados por ele são estudados por várias disciplinas, entre as quais estão as teorias da enunciação (BENVENISTE, 2006; BAKHTIN, 2003), a pragmática (MAINGUENEAU, 1996, 2002), a análise conversacional (KERBRAT-ORECCHIONI, 2006) e a sociolinguística. Quanto à sociolinguística, os trabalhos de Labov (2008) foram os primeiros a utilizar a variação estilística como procedimento metodológico importante para determinar o vernáculo, ou seja, o registro de fala em que ocorre o menor grau de monitoramento do falante no sentido de ajustar seu discurso a níveis de maior formalidade. Contudo, embora a sociolinguística se caracterize por propor um estudo social da língua, em geral, os contextos de fala propostos por Labov (2008) para verificar a variação estilística (entrevista, testes de reação subjetiva, leitura monitorada, entre outros) não correspondem a qualquer situação social concreta, ou seja, que tivesse qualquer vínculo com as práticas sociais efetivamente vivenciadas ou vivenciáveis pelos sujeitos.

$\mathrm{Da}$ forma como apresentada na metodologia laboviana, a variação contextual não busca compreender como a variação estilística afeta o envolvimento dos sujeitos nas práticas sociais (ECKERT; McCONNELL-GINET, 1992; ECKERT, 2012) ou em que medida os gêneros textuais decorrentes dessas práticas exercem possíveis coerções sobre as adequações que os falantes precisam fazer quando usam a língua em situações reais de comunicação. Trata-se, na verdade, de um procedimento por meio do qual o pesquisador cria situações devidamente controladas e conduzidas de maneira a eliciar ocorrências de dados linguísticos de acordo com os objetivos de pesquisa.

A falta de vínculo da variação estilística do modelo laboviano com a realidade social em que as práticas comunicativas interpelam os sujeitos reais tem relação com a forma como Labov (2008, p. 313) concebe a variação social no quadro teórico da sociolinguística:

A variação social e estilística da língua desempenha papel importante na mudança linguística? Por "social" entendo aqueles traços da língua que caracterizam vários subgrupos numa sociedade heterogênea; e por "estilística" as alternâncias pelas quais um falante adapta sua linguagem ao contexto imediato do 
ato de fala. [...] A variação social e estilística pressupõe a opção de dizer "a mesma coisa" de várias maneiras diferentes, isto é, as variantes são idênticas em valor de verdade ou referencial, mas se opõem em sua significação social e/ou estilística.

Ao restringir a variação social aos traços linguísticos que caracterizam os grupos sociais e a variação estilística às diferentes formas de se transmitir o mesmo conteúdo referencial na fala de um mesmo indivíduo, Labov situa de maneira bastante clara a natureza da sociolinguística tal qual ele a compreende: trata-se de uma disciplina que estuda a estrutura da língua entendida como heterogênea devido a fatores de ordem social. Logo, o estudo da variação social e estilística constitui etapa auxiliar cujo valor teórico está relacionado apenas aos processos de compreensão e descrição do sistema da língua.

Numa abordagem propriamente sociológica da linguagem, aquela em que a relação entre língua e sociedade é estudada tendo como foco precípuo a compreensão de aspectos constitutivos da sociedade considerando contextos reais e não a descrição da estrutura da língua, Bourdieu (2008) ressalta que o ato de falar consiste na apropriação por parte do sujeito de opções estilísticas já constituídas no e pelo uso (entre as variantes prosódicas e de articulação ou lexicológicas e sintáticas). Assim, ao optar por uma ou outra forma dos estilos expressivos disponíveis, o sujeito se situa na ordem da hierarquia dos grupos correspondentes e esse posicionamento institui um sistema de diferenças sociais. A variação estilística é entendida, então, não como um recurso metodológico utilizado para a coleta de dados linguísticos, mas como sistema de diferenças classificadas e classificantes, hierarquizadas e hierarquizantes, que marca aqueles que dela se utilizam. Nesse caso, uma vez que a necessidade de comunicação entre pessoas de grupos diferentes é uma constante nas sociedades complexas, não serão raras as situações de conflitos decorrentes de tensões entre dois processos que deveriam ser complementares: a produção e a reprodução de uma língua comum, entendida como legítima, e sua distribuição igual pelos grupos. Com base nesses pontos, faz todo sentido a crítica que Bourdieu (2008, p. 41-42) dirige à forma como o social tem sido tratado pela linguística: 
Ao privilegiar as constantes linguisticamente pertinentes em detrimento das variações sociologicamente significativas para construir este artefato que é a língua "comum", tudo se passa como se a capacidade de falar, mais ou menos universalmente difundida, fosse identificável à maneira socialmente condicionada de realizar esta capacidade natural, cujas variedades são tantas e quantas sejam as condições sociais de aquisição. A competência suficiente para produzir frases suscetíveis de serem compreendidas pode ser inteiramente insuficiente para produzir frases suscetíveis de serem escutadas, frases aptas a serem reconhecidas como admissiveis em quaisquer situações nas quais se pode falar. Também neste caso, a aceitabilidade não se reduz apenas à gramaticalidade. Os locutores desprovidos de competência legítima se encontram de fato excluídos dos universos sociais onde ela é exigida, ou então, se veem condenados ao silêncio. Por conseguinte, o que é raro, não é a capacidade de falar, inscrita no patrimônio biológico, universal e, portanto, essencialmente não distintiva, mas, sim, a competência necessária para falar a língua legítima que, por depender do patrimônio social, retraduz distinções sociais na lógica propriamente simbólica dos desvios diferenciais ou, numa palavra, da distinção. (Grifos do autor)

A posição de Bourdieu acerca do papel social da língua legítima (padrão) e suas implicações para estudos de sociologia da linguagem contrasta com as ideias comumente difundidas pelos sociolinguistas variacionistas. Labov, desde o início, definiu a fala vernácula como objeto de estudo da sociolinguística. Os sociolinguistas brasileiros também rejeitaram a língua padrão como objeto de estudos científicos. Mesmo quando defendem o princípio da adequação do uso da língua ao contexto, argumento muito utilizado para justificar a rejeição dos acadêmicos à noção de erro de português, fundamentam a crítica em bases naturais, ou seja, em conformidade com o pressuposto de que a língua tem suas próprias regras. No entanto, quando se avaliam os usos sociais efetivos da língua, aí incluída a variação estilística, não está em questão a capacidade natural, biológica do locutor para falar, e sim sua competência para usar os estilos aceitáveis e admissíveis em diferentes contextos sociocomunicativos, inclusive aqueles em que se exige o domínio da língua padrão.

Outro problema que pode ser considerado no princípio da adequação é seu caráter pseudocientífico. Aqueles que o defendem veem- 
no como uma espécie de conclusão de um raciocínio silogístico cujas premissas seriam fundamentadas em resultados de pesquisas científicas. No entanto, como a metodologia variacionista da chamada "primeira onda da sociolinguística" (ECKERT, 2012) não contempla a variação estilística em situações efetivamente reais, a conclusão de que os falantes costumam adequar o uso linguístico às situações comunicativas em que se encontram é, na verdade, um truísmo cuja compreensão independe de pesquisas ou de qualquer respaldo de natureza científica, como bem observou Corbeil (2001, p. 201): “O paradoxo de uma língua de grande difusão é integrar a variação sempre respeitando uma norma unificadora. $\mathrm{O}$ paradoxo parece se resolver mais comodamente no exercício da língua pelos falantes do que nas reflexões daqueles que falam dela oficialmente".

Os desenvolvimentos futuros do tratamento da variação estilística, sobretudo após a adoção do conceito de norma como índice de processos de hierarquização social, a partir do qual a sociolinguística estabeleceu os conceitos classificatórios de norma culta e norma popular, não representaram um desvio da metodologia laboviana concernente ao funcionamento da variação estilística nas práticas sociais. A esse respeito, é oportuna a crítica de Lucchesi ao tratamento da variação estilística no âmbito do Projeto de Estudo da Norma Linguística Urbana Culta ${ }^{2}$ (NURC), em cujos dados muitos pesquisadores têm-se baseado para defender a legitimidade da norma culta em oposição à norma padrão:

Embora possa ser considerado o primeiro grande projeto de pesquisa sociolinguística desenvolvido no Brasil, o NURC não segue a metodologia laboviana. Assim, as suas entrevistas não adotam os procedimentos sugeridos por Labov para superar o paradoxo do observador e obter uma amostra do vernáculo do falante. As entrevistas ainda seguiam a metodologia da dialetologia tradicional e tinham por tema determinada área lexical (como alimentação, viagem, vestuário etc.). Com isso, o nível de formalidade das entrevistas não foi controlado e é variável, comprometendo a observação dos dados no que concerne à variação estilística. (LUCCHESI, 2015, p. 219)

\footnotetext{
${ }^{2}$ Os acervos de fala "culta" do NURC foram constituídos na década de 1970, em cinco capitais brasileiras: Porto Alegre, São Paulo, Rio de Janeiro, Salvador e Recife. A coleta de dados se deu por meio de entrevistas com falantes naturais das cinco capitais, todos com nível superior completo.
} 
Apesar dos problemas metodológicos identificados no NURC, Lucchesi defende o que considera como contribuições de estudos sobre a modalidade oral da norma culta brasileira, partir dos acervos do Projeto, para uma discussão pública sobre a normatização linguística no Brasil. Sendo assim, como aceitar que estudos realizados com base em dados coletados por meio de uma metodologia reputada como problemática constituam referências para o debate sobre a padronização linguística no país? Como aceitar, num país com a extensão territorial e a diversidade sociocultural do Brasil, que se defina uma norma culta pretensamente amparada em dados reais da fala nacional por meio de amostras da língua falada unicamente por falantes de nível superior de apenas cinco capitais do país, tal como se verifica no Projeto de Gramática do Português Falado (JUBRAN; KOCH, 2006; ILARI E NEVES, 2008; KATO; NASCIMENTO, 2009)? Afinal, o nível superior é condição suficiente para alguém ser considerado falante culto de uma língua num país como o Brasil, em que a qualidade da educação básica está bastante aquém do desejável e tem levado muitos estudantes com formação precária para as universidades? Sabemos bem que os cursos de nível superior não reservam espaço em seus currículos para desenvolver atividades capazes de remediar as precariedades decorrentes de uma formação ineficiente na educação básica.

As respostas a essas questões têm sido causas de uma série de divergências entre os pesquisadores. Entre eles, a designação norma culta tem-se mostrado problemática não necessariamente pelo fato de $o$ qualificativo "culta" revelar um comprometimento ideológico do discurso científico, que passa a instituir formas de distinção social, quando, na verdade, deveria analisar as formas de distinção em vigor na sociedade. A principal dificuldade que os sociolinguistas encontram para lidar com a diferenciação social marcada pela instituição da norma culta tem ligação com outro termo classificatório que seria sua contraparte natural: como o antônimo de culta é inculta, a norma culta deveria instituir de imediato seu oposto para recobrir todos os usos linguísticos que fogem de seu escopo, ou seja, a norma inculta. No entanto, diante de razões sócio-antropológicas bastante razoáveis, optou-se pela solução aparentemente mais simples: manter a norma culta e instituir, não sem grande carga de arbitrariedade no âmbito do próprio signo, a norma popular como seu contraponto. 
Apesar do esforço empreendido pelos pesquisadores para marcar de maneira bastante incisiva a distância teórica e política que separa ambas as normas, paira no senso comum, no discurso pedagógico referente ao ensino de língua portuguesa e em trabalhos de muitos linguistas, uma identificação entre norma culta e norma padrão, entendida como equivocada por pesquisadores de formação sociolinguística mais especializada. Os que defendem a distinção entre essas normas denunciam a língua padrão como um modelo idealizado e artificial de língua fortemente comprometido com processos de dominação e exclusão social das classes dominantes sobre as classes populares (FARACO, 2008; LUCCHESI, 2015). A nova concepção de norma culta, por sua vez, não obstante sua controversa correlação com o grupo ou grupos sociais de referência, é consensualmente entendida como a variedade linguística efetivamente utilizada pelos falantes mais escolarizados, distinguindo-se estruturalmente em muitos aspectos da norma padrão. Por esse motivo, é vista por seus proponentes como a real língua do Brasil, razão pela qual os sociolinguistas aplicados a elegeram como referência para as discussões sobre a padronização linguística. Adotando essa posição, relegaram a norma padrão a uma espécie de limbo, ou seja, a um lugar de indefinição tanto no contexto acadêmico quanto no escolar. Esse gesto suscita o seguinte problema: uma ciência aplicada que se propõe ao estudo das relações entre língua e sociedade pode excluir deliberadamente de seu campo de interesse a língua institucionalizada, histórica e socialmente reconhecida como padrão?

\section{A resposta da sociolinguística positivista brasileira}

As justificativas para a exclusão da norma padrão do conjunto de objetos de estudo da sociolinguística revelam, antes de tudo, sua filiação ao paradigma científico positivista, segundo o qual os critérios de cientificidade das pesquisas devem estar alinhados aos estabelecidos pelas ciências naturais. Isso explica o fato de autores como Perini ${ }^{3}$ e

\footnotetext{
${ }^{3}$ Após negar que o estudo de gramática tenha alguma contribuição a dar para que os estudantes desenvolvam capacidades de leitura e escrita, Perini estabelece qual deve ser seu lugar na escola: “[...] o que a gramática poderia fazer enquanto disciplina escolar? Minha resposta é que a gramática é uma disciplina científica, tal como a química, a geografia e a biologia. Assim como a biologia estuda os seres vivos (sua forma, fisionomia, hábitos, etc.) e a química estuda os elementos e suas combinações,
} 
Bagno, ${ }^{4}$ entre vários outros, propugnarem que o estudo da língua e/ou gramática deva receber na escola o mesmo tratamento de disciplinas científicas como a química, a física, a biologia e a geografia, por exemplo.

A sociolinguística laboviana segue à risca os princípios epistemológicos do paradigma positivista (HUGHES, 1983) no tocante à objetividade ou neutralização da influência do pesquisador na observação dos fenômenos estudados, na metodologia proposta para o tratamento da variação estilística e em suas sugestões para minimizar o chamado paradoxo do observador, ou seja, o desafio que o pesquisador enfrenta para descobrir como as pessoas falam quando não estão sendo monitoradas, visto que só é possível obter esses dados por meio de alguma técnica que pode induzir o falante ao monitoramento de sua fala (LABOV, 2006). Acrescenta-se a essa lista a forma como se concebe a delimitação do campo disciplinar. Labov (2008, p. 215) circunscreve a sociolinguística ao estudo da "língua em uso dentro da comunidade de fala, com vistas a uma teoria linguística adequada para dar conta desses dados". Mais adiante, na mesma obra (p. 216), reafirma que seu objetivo é estudar a estrutura e a evolução da língua dentro do contexto social da comunidade de fala, considerando exclusivamente tópicos da linguística geral, quais sejam, da fonologia, morfologia, sintaxe e semântica. Parece ficar bem claro que o estudo dos usos da língua dentro da comunidade de fala está a serviço do desenvolvimento da teoria linguística e não da compressão das relações entre língua e sociedade. Essa hipótese se confirma quando o pesquisador, ainda atendendo a propósitos de delimitação disciplinar, distingue a sociolinguística da sociologia da linguagem:

Uma área de pesquisa que tem sido incluída na "sociolinguística" talvez seja rotulada mais adequadamente de "sociologia da linguagem". Lida com fatores sociais de larga escala e sua interação mútua com línguas e dialetos. Há várias questões

a gramática estuda um aspecto da linguagem - um fenômeno tão presente em nossas vidas quanto os seres vivos ou os elementos químicos (PERINI, 2010, p. 35).

${ }^{4}$ Bagno vê como necessário um ensino de língua fundado em bases científicas, livre do senso comum: "A educação linguística precisa ter como base as teorias e metodologias contemporâneas das ciências da linguagem e da educação, das ciências sociais e humanas, e não um aparato obsoleto e pré-científico". (BAGNO, 2010, p. 25). Para conhecimento de críticas de pensadores da área de educação ao modelo de ensino orientado pela ciência, ver Zaballa (2002) e Perrenoud (2002, p. 89-106). 
abertas e diversos problemas práticos associados com o declínio e a assimilação de línguas minoritárias, o desenvolvimento do bilinguismo estável, a padronização de línguas e o planejamento do desenvolvimento da língua em nações recém-surgidas. O estímulo linguístico para esses estudos é primordialmente o de que dada pessoa ou grupo usa a língua $X$ num contexto ou domínio social Y. (LABOV, 2008, p. 215) (Aspas do autor, negritos meus)

A distinção entre as disciplinas, tal qual propõe Labov, está na maior ou menor ênfase concedida aos aspectos da estrutura da língua ou aos fatores sociais mais amplos. Assim, a sociolinguística estaria "preocupada com as formas das regras linguísticas, sua combinação em sistemas, a coexistência de vários sistemas e a evolução dessas regras e sistemas com o tempo" (LABOV, 2008, p. 216). Em contrapartida, os aspectos práticos ligados ao funcionamento social da língua, entre os quais se incluem as políticas linguísticas, seu planejamento e seus instrumentos, seriam objetos da sociologia da linguagem.

A hegemonia do paradigma positivista nas ciências sociais passou a ser objeto de muitas contestações e hoje já é possível afirmar que se trata de um modelo amplamente superado no campo das ciências humanas. Um olhar, mesmo superficial, sobre suas características é suficiente para entendermos as razões dessa virada. Santos (2008) apresenta as seguintes características desse paradigma ainda dominante no campo da sociolinguística variacionista: i) modelo totalitário, na medida em que nega qualquer racionalidade a todas as formas de conhecimento que não se pautarem pelos seus princípios epistemológicos e por suas regras metodológicas. Esse princípio instaura a cisão entre conhecimento científico (válido) e senso comum (conhecimento inválido); ii) o conhecimento científico avança pela observação descomprometida e isenta de subjetividade, sistemática e rigorosa dos fenômenos estudados; iii) conhecer significa quantificar. O rigor científico é consequência do rigor das medições; logo, o que não é quantificável é cientificamente irrelevante; iv) o método científico se assenta na redução da complexidade. Conhecer significa dividir e classificar para, depois, poder determinar as relações entre as partes separadas; v) é um conhecimento causal que aspira à formulação de leis, com base nas regularidades observadas a fim de prever o comportamento futuro dos fenômenos. As leis são um tipo de causa formal que privilegia o como funciona as coisas em detrimento de qual o agente ou qual o fim das coisas. Todas essas características, 
presentes na metodologia laboviana, opõem-se a características que Santos (2008, p. 36) considera constitutivas das ciências humanas:

As ciências sociais não dispõem de teorias explicativas que lhes permitam abstrair do real para depois buscar nele, de modo metodologicamente controlado, a prova adequada; as ciências sociais não podem estabelecer leis universais porque os fenômenos sociais são historicamente condicionados e culturalmente determinados; as ciências sociais não podem produzir previsões fiáveis porque os seres humanos modificam seu comportamento em função do conhecimento que sobre ele se adquire; os fenômenos sociais são de natureza subjetiva e como tal não se deixam captar pela objetividade do comportamento; as ciências sociais não são objetivas porque o cientista social não pode libertar-se, no ato da observação, dos valores que informam sua prática em geral e, portanto, de sua prática de cientista.

Se essa é a condição da sociolinguística face à oposição entre a restrição de seu campo ao estudo das formas linguísticas e as complexidades do funcionamento social da língua, como explicar o crescente interesse dos sociolinguistas de formação variacionista por temas como padronização linguística e ensino de língua e as posições veementes que têm manifestado a respeito dessas questões? Penso que estamos mais uma vez diante do transbordamento semântico do social como elemento de composição que forma o nome da disciplina sociolinguística. Isso já aconteceu na passagem da concepção de língua de Saussure para a de Labov e está acontecendo na sociolinguística brasileira em virtude de seu alinhamento com as teorias sociais de base marxista que estão na base das interpretações dos sociolinguistas a respeito do caráter heterogêneo da língua e suas implicações sociais. Uma das principais razões desse transbordamento do social em relação ao modelo laboviano está naquilo que é tido como sua incapacidade de apreender os conflitos sociais decorrentes da variação social e estilística. Como alternativa para as limitações do modelo do consenso social adotado por Labov, Lucchesi (2015) propõe a manutenção dos procedimentos metodológicos essenciais da sociolinguística, seguida de uma nova forma de interpretar os resultados das pesquisas.

$\mathrm{Na}$ verdade, da intenção de Lucchesi de salvar o edifício teórico-metodológico da sociolinguística laboviana, surgiu uma solução aporética. Isso porque, enquanto no modelo de Labov havia um 
programa de pesquisas coeso, em que a metodologia estava a serviço da explicação da mudança linguística - e era esse o objetivo das pesquisas sociolinguísticas -, a solução de Lucchesi defende o uso da metodologia de Labov para explicar os conflitos sociais decorrentes da avaliação social da variação linguística. Cabe questionar, nesse caso, se a interpretação social dos conflitos que tem sido feita pelos linguistas é realmente amparada na metodologia empregada ou se seria possível formulá-la independentemente da metodologia sociolinguística.

Essa seria uma questão relevante por dois motivos: primeiro porque há várias publicações em que os autores apresentam discussões de cunho social a respeito da variação sem terem desenvolvido nenhum projeto de pesquisa utilizando a metodologia laboviana (FARACO, 2008; FARACO, ZILLES, 2015; BAGNO, 2009; MATTOS E SILVA, 2005); segundo porque é bastante discutível que dados quantitativos sobre a variação linguística, coletados por meio de uma metodologia marcada pelo apagamento da subjetividade e por dados produzidos em condições artificiais de uso da linguagem, justifiquem, automaticamente, as teses sobre a falta de legitimidade da língua padrão. Disso decorre outro problema importante: a separação entre pesquisa e interpretação. Os autores que publicam trabalhos de cunho sociológico, com ênfase na suposta relação conflituosa entre a variação linguística e sua avaliação social, afirmam que suas interpretações estão amparadas nos dados de pesquisas. No entanto, o que efetivamente se verifica é que a avaliação social da variação, componente importante da metodologia de Labov, teve sua importância minimizada na pesquisa sociolinguística brasileira. Assim, as afirmações sobre os conflitos sociais decorrentes da variação não se amparam nos dados coletados pela metodologia sociolinguística. A assunção do princípio da heterogeneidade linguística torna a simples ocorrência de qualquer variante linguística empregada pelos falantes, ainda que não seja objeto de pesquisas sociolinguísticas específicas, como suficiente para subsidiar interpretações sobre as relações entre língua e sociedade.

Diante da separação entre pesquisa e interpretação ou, em outros termos, entre teoria linguística e teoria social, é preciso avaliar se o desenvolvimento disciplinar ou interdisciplinar das áreas envolvidas consegue responder de maneira satisfatória ao problema da padronização linguística, como tem feito os sociolinguistas aplicados. A primeira 
questão suscitada é se isso constitui, de fato, um objeto de estudo das disciplinas envolvidas em nível mono ou interdisciplinar.

Labov sempre se mostrou refratário à designação "sociolinguística" por considerar que, dado o caráter eminentemente social da língua, seria um contrassenso pensar uma teoria linguística geral que não fosse social. Então, mesmo após ter acatado a designação, é possível questionar se ele situa a teoria que propõe no campo da interdisciplinaridade. Por outro lado, a distinção que propõe entre sociolinguística e sociologia da linguagem, seguida de seus respectivos objetos, parece deixar muito claro que a padronização seria objeto apenas da segunda. Como bem frisou, o estudo desses objetos mais amplos só apresenta em comum com os objetos da teoria linguística o fato de considerar que o falante usa determinada língua em determinado contexto.

Relacionando a posição de Labov com o estágio atual da sociolinguística aplicada brasileira, seria coerente afirmar que houve uma passagem do campo disciplinar para o interdisciplinar, condição necessária para que fosse possível abordar, de maneira satisfatória, um objeto tão amplo como a padronização linguística. No entanto, para isso, seria necessária também a revisão de sua metodologia. Já vimos, porém, que Lucchesi (2015) defende a manutenção dos princípios básicos da metodologia laboviana. Verifica-se, dessa forma, a existência de dois campos distintos no interior da sociolinguística tal qual vem se desenvolvendo no Brasil: um que investiga processos de variação e mudança, caracterizando a pesquisa sociolinguística propriamente dita ou ciência pura, e outro que se baseia nesses dados para realizar interpretações sobre a avaliação social da variação, além de questões ligadas à padronização linguística. A segunda acepção estaria, a rigor, no âmbito da sociologia da linguagem e seria classificada como ciência aplicada. A distinção entre esses campos é fundamental para uma avaliação adequada dos saberes oriundos da investigação sociolinguística e de suas possibilidades de aplicação. Penso que a falta de clareza quanto a essa distinção está na base dos projetos reformistas de alguns sociolinguistas aplicados, que buscam a transferência direta dos resultados de pesquisa para contextos sociais mais amplos do que os previstos nos objetivos das investigações que os produziram.

Quanto a esse ponto, poder-se-ia objetar que as interpretações sociais são feitas com base nos dados. Como essa objeção só faria sentido se houvesse uma relação interdisciplinar entre os campos, torna- 
se necessário avaliar a pertinência e a adequação das teorias e métodos compartilhados, a fim de verificar se há realmente uma relação harmônica entre ambos a ponto de constituírem uma única disciplina.

Toda disciplina se caracteriza pela definição de um quadro teórico e da concepção metodológica de que se utiliza no processo de produção do conhecimento sobre os fenômenos que estuda. A indissociabilidade entre teoria e método é, portanto, condição sine qua non para a constituição de uma disciplina. É essa relação constitutiva que explica, por exemplo, as diferenças entre os pensadores da teoria social clássica: Durkheim, com o método funcionalista, Marx, com o materialismo, e Weber, com os tipos ideais. Em abordagens interdisciplinares, a falta de harmonia entre teoria e método acarreta sempre o risco de que sejam reunidas, em um mesmo contexto, posições teóricas formalmente válidas, mas totalmente incompatíveis do ponto de vista metodológico ou dos paradigmas em que cada uma se encontra. Essas são observações fundamentais para que não se confunda a interdisciplinaridade com uma bricolagem intuitiva.

Diante desse quadro, a classificação da sociolinguística como campo interdisciplinar impõe que desconsideremos a independência entre teoria linguística e teoria social (a separação entre pesquisa e interpretação não teria sentido). Sendo assim, podemos apresentar, de maneira mais explícita, o problema que queremos discutir: a sociolinguística aplicada brasileira coaduna objetos, teorias e métodos da linguística e da teoria social de maneira suficientemente harmônica em sua constituição interdisciplinar? Esse problema só pode ser satisfatoriamente abordado se examinarmos os aspectos teórico-metodológicos que cada uma oferece para o compartilhamento e como essas contribuições passaram a funcionar no projeto de reconfiguração da disciplina.

A sociolinguística surge com o objetivo de explicar a mudança linguística (WEINREICH; LABOV; HERZOG, 2006). Labov verificou que, antes de uma mudança se consolidar, os fenômenos linguísticos observados passam por uma fase de transição ${ }^{5}$. Diante da constatação de que há sempre formas em variação ou em competição no interior do sistema da língua, sem que isso implique qualquer prejuízo ao seu funcionamento, concluiu que a língua é um sistema heterogêneo. É importante assinalar que a heterogeneidade, em si, não representa uma

\footnotetext{
${ }^{5}$ Labov observou também que nem todas as vezes que formas linguísticas estavam em variação havia mudança.
} 
novidade trazida pela linguística, como se pode erroneamente supor. A novidade está no valor que a linguística laboviana lhe confere como fenômeno que possibilita explicar a mudança.

Outro princípio metodológico importante da teoria laboviana é o reconhecimento de que a variação só é verificável por meio do uso da língua pelos falantes situados em comunidades de fala. A verificação da heterogeneidade linguística no contexto social levou à conclusão de que todas as variantes ou variedades da língua são sistemáticas, ou seja, são produzidas de acordo com as regras possíveis de estruturação do sistema da língua. Essa conclusão, plenamente defensável do ponto de vista de uma teoria linguística positivista, redunda em um problema sociológico básico: se todas as variantes e variedades são igualmente sistemáticas, o que justifica o prestígio de umas e a estigmatização social de outras?

Embora essa não fosse uma questão passível de explicação por meio de uma teoria linguística, Labov não a ignorou de todo. Antes, buscou compreender de que maneira a avaliação social sobre a variação poderia contribuir para a mudança linguística, chegando à conclusão de que a estratificação social exerce influência considerável nesse processo. Não era seu interesse abordar processos sociais mais amplos. Essa ausência de discussão sociológica não pode simplesmente ser atribuída a uma falta de vontade ou de compreensão de Labov acerca dos impactos socioideológicos da avaliação social da variação estilística, mas ao reconhecimento das limitações da metodologia adotada, tendo em vista os objetivos de seu projeto investigativo, que tinha como foco a explicação da mudança linguística.

A falta de uma teoria social que possibilitasse uma abordagem dos conflitos sociais em consequência da avaliação social negativa de variantes estigmatizadas foi considerada por Lucchesi (2015) como a principal limitação da sociolinguística laboviana, e essa se tornou uma questão proeminente no desenvolvimento da sociolinguística. O problema é que, nesse caso, não existe apenas uma teoria social que possa servir de base para explicar as relações sociais, como ocorre no caso do tratamento da variação linguística. Considerando que cada teoria social busca constituir-se como um modelo geral de análise e explicação da sociedade, é sempre crucial conhecer as razões que levam um pesquisador à escolha de uma ou outra abordagem. Esse não é um problema de pouca monta, pois, ainda que essa escolha possa se mostrar amparada em critérios 
objetivos, não podemos perder de vista que a marca mais característica do ato de escolher é a subjetividade.

A sociolinguística brasileira considerou a tese da ideologia dominante como mais adequada para explicar a forma como as variedades linguísticas são valoradas socialmente e os conflitos que daí podem advir. $\mathrm{O}$ argumento central dessa tese, de base marxista, consiste em afirmar que as classes subordinadas tendem a aceitar sua condição porque a cultura em que vivem é controlada por classes dominantes. Esses grupos, detentores do capital e dos bens culturais socialmente mais valorizados, teriam o controle das instituições educacionais e da mídia, de maneira que delas se utilizariam para transmitir seus valores e, dessa forma, garantir a reprodução de uma ordem social que fosse amplamente favorável à manutenção de um status quo marcado, prioritariamente pela manutenção de privilégios que não apenas produzem como também reforçam as desigualdades sociais. Essa ordem social seria naturalizada por meio de diversos dispositivos ideológicos que ocultariam das classes dominadas a verdadeira face da realidade. A tese da ideologia dominante assentase em dois fundamentos teórico-metodológicos da teoria marxista: o materialismo e o determinismo econômico.

Apresentados os aspectos da teoria linguística e da teoria social utilizados pelos linguistas na constituição de uma sociolinguística interdisciplinar, restam ainda duas tarefas a cumprir: caracterizar essa nova disciplina e avaliar suas condições para abordar a questão da padronização linguística.

A primeira e mais notável mudança na caracterização da disciplina está na definição de seus objetivos. Se no modelo laboviano o objetivo geral era explicar a mudança linguística e, nesse contexto, o estudo da variação representava um objetivo específico, na sociolinguística interdisciplinar, o foco se desloca para a avaliação social da variação linguística sem se apoiar numa concepção atomista de comunidade de fala, mas levando-se em conta toda a extensão territorial coberta por um idioma. Para isso, seria necessário, numa metodologia orientada rigorosamente para uma compreensão ampla do objeto, que fossem realizadas coletas de dados que pudessem constituir amostras representativas de toda a realidade sociolinguística do país.

Essa concepção ampliada dos limites da comunidade de fala, ainda um ideal teórico, levou em conta a tese da ideologia dominante e, em razão disso, correlacionou variedades de prestígio a classes 
dominantes e variedades estigmatizadas a classes subordinadas ou populares. Assim, a avaliação negativa dos usos linguísticos das classes populares passou a ser vista como extensiva aos próprios membros dessas classes. Como consequência desse processo de classificação fundado em critérios socioideológicos, e sem nenhuma justificativa baseada nos dados de pesquisa, a avaliação social negativa da fala popular foi classificada pelos sociolinguistas como expressão de preconceito linguístico. Ainda com base nos dados e conclusões da pesquisa empírica, os sociolinguistas passaram a conceber a língua padrão como um modelo de língua idealizado, em total desacordo com a realidade linguística do país e imposto pela classe dominante, para garantir às elites letradas a reprodução de uma sociedade marcada pela garantia de privilégios para poucos e a exclusão de muitos.

A alternativa para o problema, no entanto, não poderia ser mais paradoxal. Numa acintosa negação da tese da ideologia dominante, os linguistas penderam para o lado dos aspectos exclusivamente linguísticos da disciplina em detrimento dos sociais. Mantendo a correlação entre variedades linguísticas e classes sociais, instituíram uma oposição entre norma ideal (padrão) - abstrata, idealizada, distante da realidade linguística brasileira -, e normas reais (cultas e populares) concretas, condizentes com o uso efetivo dos falantes em suas práticas comunicativas. Nessa nova classificação, a norma popular continuou refletindo os usos linguísticos estigmatizados. No entanto, se a norma padrão teve sua validade negada do ponto de vista científico, a que classe social a norma culta estaria correlacionada? Ainda que o NURC tenha usado o critério da escolaridade (nível superior completo) e não o da classe social para definir o falante culto, se levarmos em conta que, no período da coleta de dados (década de 1970), o acesso à universidade era privilégio de poucos no país, seremos conduzidos à conclusão de que a maioria desses sujeitos pertencia à elite. Dessa forma, a primazia do linguístico sobre o social recoloca o problema da separação entre a teoria linguística e a teoria social no âmbito de uma sociolinguística supostamente interdisciplinar.

Os problemas mostrados nas etapas anteriores acabaram por antecipar as respostas ao terceiro aspecto a ser examinado. De fato, se as soluções apresentadas ao problema da avaliação social da variação linguística contrariam as pretensões de construção de uma abordagem interdisciplinar, o questionamento da competência da sociolinguística 
para abordar a padronização linguística se impõe como uma consequência lógica. Apesar disso, há certos aspectos conceituais e metodológicos que, por refletirem posições amplamente consensuais no meio acadêmico, merecem um exame, ainda que breve.

No âmbito da teoria linguística, a tese de que a norma culta deve ser a base para os projetos de padronização esbarra, inicialmente, no problema da falta de critérios por meio dos quais seja possível estabelecer quem seria o falante culto ou quais usos seriam considerados cultos. $\mathrm{Na}$ seção anterior foram apresentados alguns problemas metodológicos do projeto: população de amostra muito reduzida (apenas falantes de cinco capitais), falta de rigor nas estratégias de coleta de dados e controvérsias relacionadas aos critérios para definição do falante culto. Faraco (2008) reconhece a arbitrariedade dos critérios utilizados pelo NURC para definir o falante culto e adverte que esse é um dos nós que precisam ser desatados para a se estabelecer a norma culta:

O primeiro deles - e não certamente o menor - é saber quem são os letrados da sociedade brasileira, ou seja, qual ou quais grupos sociais servem de referência para delimitarmos objetivamente os fenômenos que constituem a norma culta brasileira.

Como vimos anteriormente, o projeto NURC restringiu a classificação de "cultos" (de mais letrados) aos falantes com educação superior completa. No entanto, numa sociedade que distribua de maneira mais equânime os bens educacionais e culturais, é mais adequado considerar letrados todos os que concluem pelo menos o ensino médio. Este é um critério que se constitui historicamente nas sociedades industriais modernas nos últimos duzentos anos. (FARACO, 2008, p. 59).

Mattos e Silva (2005, p. 78-79) admite a impossibilidade de se definir a norma padrão com base na realidade linguística, um dos objetivos do NURC: "impossível, parece-me, será estabelecer uma norma padrão com base na realidade linguística. Esse padrão estará sempre carregado de arbitrariedade". Bagno (2011) considera que os dados do NURC, coletados na década de 1970, não representam com fidelidade a norma culta contemporânea. Apesar de todos esses problemas, devido ao fato de o NURC ser o único projeto com acervos de fala definida como culta pelos pesquisadores, muitos linguistas têm-se baseado nesses acervos para fundamentar suas posições acerca da padronização linguística. Outro problema está na proposta de substituir um padrão tido como 
ideal por outro tido como real, tomando como base a modalidade falada da língua. Essa decisão atende aos princípios do paradigma positivista em nome do qual se busca o alinhamento da prática científica com a metodologia das ciências naturais. Nesse sentido, é preciso apreender a ordem interna do sistema linguístico por meio de sua manifestação natural para, em seguida, estabelecê-la como referência para a ordem social. Já mencionamos, na seção anterior, o contraste que Bourdieu estabelece entre a capacidade biológica de falar uma língua e a competência para utilizar a língua legítima (padrão) em situações comunicativas específicas. Ocorre que, na sociolinguística, o real só pode ser entendido como sinônimo de natural, uma vez que é impossível negar a realidade social da língua padrão, presente em diversas práticas sociais.

Um projeto de padronização linguística baseado na modalidade falada teria de resolver, ainda, o problema da relação entre sincronia e diacronia. A língua padrão, da forma como a conhecemos, está intrinsecamente ligada à modalidade escrita desde o seu surgimento. Essa característica tem sido alvo de críticas dos linguistas, primeiro por atribuir um lugar secundário à língua falada (não à oralidade), depois por conservar aspectos formais e estruturais da língua muito distantes dos conhecimentos linguísticos dos falantes. Contudo, uma das características mais marcantes de sociedades historicamente letradas é o acúmulo de grandes quantidades de materiais escritos que atravessaram séculos e até milênios, sem que isso afete sua atualidade ou importância como patrimônio histórico-cultural. Além disso, a língua padrão constitui um instrumento que possibilita estruturar práticas sociocomunicativas nos mais diversos campos da atividade humana, desde as mais tradicionais às mais modernas. Ou seja, a língua padrão é capaz de contemplar tanto aspectos sincrônicos quanto aspectos diacrônicos. Os estudos sobre a língua falada, ao contrário, concentram-se apenas numa abordagem sincrônica e, por essa razão, jamais poderiam servir de referência para a padronização linguística, uma vez que não teria como integrar formas e estruturas da língua muito recuadas no tempo.

Os problemas apresentados nesta seção corroboram a posição de Rajagopalan no tocante à distinção entre ciência linguística e política linguística, reafirmando, em outros termos, a especificidade da sociologia da linguagem em relação à sociolinguística: 
[...] muitos se apressam para pleitear que o fato de ter sido treinado como linguista deve propiciar uma nítida vantagem a uma pessoa quando se trata de opinar sobre questões de política linguística. MINHA RESPOSTAÉ UM SONORO NÃO. Explico. $\mathrm{O}$ conhecimento que o linguista diz ter é um conhecimento científico sobre a estrutura e o funcionamento das línguas. Ele sabe, por exemplo, que a estrutura fonológica de uma língua funciona com base em contrastes e complementaridades entre unidades e não entre sons fisiológica ou acusticamente distintos. Mas, conhecimentos desse tipo não tem nada a ver com questões que interessam no campo da política linguística.

A posição do linguista em relação aos assuntos de interesse político que envolve a língua é idêntica à do biólogo ou ginecologista, ou jurista, ou quem quer que seja em relação à decisão de legalizar aborto. (RAJAGOPALAN, 2013, p. 23) (Grifo do autor).

\section{Problemas da teoria social na sociolinguística brasileira}

No contexto da teoria social, a tese da ideologia dominante representa o alinhamento da linguística ao que foi chamado, na sociologia, de "consenso ortodoxo" (GIDDENS, 2009), um conjunto de proposições explicativas baseadas na teoria social clássica, que teve grande influência na forma como se analisavam as sociedades até o final da década de 1960 e início da de 1970, quando surgiu outro conjunto de perspectivas teóricas concorrentes que provocou a dissolução de praticamente todo o consenso anterior. Conquanto apresentassem divergências teóricas, as novas vozes se alinharam na rejeição a um princípio básico do consenso ortodoxo, que tinha grandes implicações na construção de seu edifício teórico-metodológico: a asserção de que o comportamento humano é consequência do funcionamento de mecanismos de poder que os sujeitos não controlam nem compreendem. É essa forma de conceber a relação entre o social e o individual que caracteriza a tese da ideologia dominante, fortemente marcada pelo marxismo ortodoxo, que orienta a teoria social utilizada pelos sociolinguistas aplicados para orientar seus projetos reformistas. Hall sintetiza bem os pontos críticos da teoria marxista que conduziram à sua rejeição pela teoria social contemporânea: 
Dizer que as ideias são "meros reflexos" estabelece seu materialismo, porém as deixa sem efeito específico, um domínio de pura dependência. Afirmar que as ideias são determinadas "em última instância" pelo econômico é tomar o caminho do reducionismo econômico. Em última análise, as ideias podem ser reduzidas à essência de sua verdade - seu conteúdo econômico. [...] Dizer que o domínio de uma classe garante o predomínio de certas ideias é dar àquela classe a posse absoluta das ideias; é também definir as formas particulares de consciência como algo específico a uma classe.

Deve-se observar que, embora estejam diretamente dirigidas contra as formulações que concernem ao problema da ideologia, essas críticas de fato recapitulam a substância de uma crítica mais geral e ampla contra o próprio marxismo: seu rígido determinismo estrutural, seu duplo reducionismo - econômico e de classe -, bem como sua forma de conceber a própria formação social. (HALL, 2003, p. 270-271)

A derrubada de princípios estruturantes do consenso ortodoxo impôs uma revisão radical das teorias e métodos de todas as áreas que, direta ou indiretamente, lidavam com objetos relacionados à vida social. $\mathrm{Na}$ teoria crítica da escola de Frankfurt, Adorno e Horkheimer (1985) destacam o papel que a indústria cultural atribui à linguagem popular na cultura de massa, incluindo a mídia de massa, como estratégia para favorecer uma comunicação mais eficaz com esse público consumidor. Foucault (1979) se opõe a uma visão exclusivamente negativa do poder como mecanismo de opressão pertencente a uma classe dominante que o exerceria contra uma classe dominada. Sua concepção de poder como uma prática difusa, como uma rede produtiva que atravessa todo o tecido social, obriga-o a rejeitar uma compreensão de ideologia fundada na ideia de ocultação de verdades que só poderiam ser percebidas pelos críticos. No âmbito dos estudos culturais, Hall propõe uma releitura das contribuições da teoria marxista, em que fica evidente a oposição à teoria da ideologia dominante e aos pontos cruciais do consenso ortodoxo:

A análise não se organiza mais em torno da distinção entre o "falso" e o "verdadeiro". O obscurecimento ou a mistificação dos efeitos da ideologia não é mais visto como um produto de truque ou ilusão mágica. Tampouco se pode atribuí-los à falta de consciência, na qual nossos pobres, ignorantes e não teóricos 
proletários estão irrevogavelmente imersos. As relações nas quais as pessoas existem são as "relações reais" que as categorias e conceitos por elas utilizadas lhes permitem apreender e articular em seu pensamento. Porém - e aqui podemos estar em um caminho contrário à ênfase à qual o "materialismo" é geralmente associado - as próprias relações econômicas não podem prescrever uma forma única, fixa e inalterável de conceber essas relações. (HALL, 2003, p. 284-285).

Os sociolinguistas aplicados têm-se mantido alheios ao debate que reavalia o potencial analítico e explicativo das contribuições do consenso ortodoxo como referencial teórico-metodológico para investigar a vida social. O qualificativo "ortodoxo" evidencia uma concepção de teoria social baseada na ideia de verdade fixa, em tudo contrária à dinâmica inerente à vida social. Nesse sentido, o consenso reflete também uma visão estruturalista de história, em que determinismo econômico, organização social em classes e ideologia aparecem como estruturas invariantes ao longo da história. Nada mais contraditório para uma teoria que surge com o objetivo de explicar a mudança linguística do que admitir a mudança da língua e, contraditoriamente, com base em uma concepção de história como continuidade, negar a mudança social. Não obstante, os sociolinguistas aplicados brasileiros continuam buscando no passado colonial as explicações causais para as desigualdades sociais que geram a exclusão social e linguística das classes populares.

No contexto das reflexões próprias da sociologia da linguagem, Bourdieu, mesmo influenciado por várias ideias da crítica marxista, nega que a legitimidade da língua padrão seja resultado de medidas jurídicas coercitivas às quais as classes dominadas simplesmente se submeteriam. Em suas palavras:

[...] os efeitos de dominação correlatos à unificação do mercado linguístico só se exercem por intermédio de todo um conjunto de instituições e de mecanismos específicos cujo aspecto mais superficial se manifesta justamente através de uma política propriamente linguística e mesmo das intervenções expressas dos grupos de pressão. E o fato de que tais efeitos pressuponham a unificação política ou econômica que eles contribuem por sua vez para reforçar não significa de modo algum que se devam imputar os avanços da língua oficial à eficácia direta de coerções jurídicas ou quase jurídicas. Tais coerções 
podem, no máximo, impor a aquisição, mas não a utilização generalizada e a reprodução autônoma da língua legítima. Toda dominação simbólica supõe, por parte daqueles que sofrem seu impacto, uma forma de cumplicidade que não é submissão passiva a uma coerção externa nem livre adesão a valores. $O$ reconhecimento da legitimidade da língua oficial não tem nada a ver com uma crença expressamente professada, deliberada e revogável, nem com um ato intencional de aceitação de uma "norma". Através de um lento e prolongado processo de aquisição, tal reconhecimento se inscreve em estado prático nas disposições insensivelmente inculcadas pelas sanções do mercado linguístico e que se encontram, portanto, ajustadas, fora de qualquer cálculo cínico ou de qualquer coerção conscientemente sentida, às possibilidades de lucro material e simbólico que as leis de formação dos preços característicos de um determinado mercado garantem objetivamente aos detentores de um certo capital linguístico. (BOURDIEU, 2008, p. 37-38) (Negritos meus)

As reflexões de Bourdieu, juntamente com as críticas ao consenso ortodoxo, revelam que, até o momento, a busca pela compreensão de como se dá o processo de fixação de uma língua padrão e suas relações com a vida social tem-se guiado por princípios teórico-metodológicos equivocados. Isso se deve, sobretudo, à concepção de ciência que tem orientado as pesquisas e a problemas com a teoria social que fundamenta as interpretações de seus resultados. Tanto a metodologia da sociolinguística quanto os recortes de teoria social que a ela se juntam na composição de sua face como ciência aplicada excluem o ponto de vista dos atores sociais envolvidos no uso da linguagem. A adoção de estratégias que visam garantir o controle da situação de coleta de dados, o apagamento da subjetividade tanto do pesquisador quanto do sujeito de pesquisa são princípios positivistas necessários à depreensão de um objeto natural e, portanto, livre da interferência humana. A utilização de aspectos de teorias sociais também orientadas por princípios teóricometodológicos que concebem o sujeito como assujeitado a forças sociais que não conhecem nem podem controlar completa o quadro de um modelo de estudos sociolinguísticos com profundas limitações para se chegar a uma reflexão adequada sobre os processos de padronização linguística. 


\section{Considerações finais}

Desde seu surgimento, a linguística está às voltas com a questão do social e seu lugar tanto na concepção quanto na descrição da língua. Em geral, nas teorias linguísticas stricto sensu, mesmo que prevaleça o consenso acerca do caráter social da língua, as metodologias de estudo enfatizam, sobretudo, os fenômenos linguísticos. Foi assim com Saussure, em Curso de linguística geral, e com Labov, que, embora considere os fatores sociais na descrição linguística, está, de fato, interessado em explicar como eles influenciam a mudança linguística. Dessa forma, a relação entre variáveis linguísticas e sociais, aí incluído o tratamento da variação estilística e sua avaliação social, tem o objetivo de possibilitar a explicação da língua como sistema heterogêneo e ordenado. Por essa razão, Labov distinguiu a sociolinguística da sociologia da linguagem.

No entanto, essa é uma posição que ainda hoje divide os linguistas. Fasold (1996) identifica duas tendências no interior da sociolinguística: uma que considera a influência de fatores sociais sobre a língua, tendo em vista a compreensão de sua natureza (a sociolinguística da língua), e uma que parte da sociedade para compreender o papel social desempenhado pela língua (sociolinguística da sociedade). A segunda, para abordar satisfatoriamente as funções sociais das línguas no âmbito da organização sociopolítica, deve abarcar a linguística antropológica e a etnografia da comunicação, o que implica reconhecer a relevância dos métodos qualitativos, que caracterizam a pesquisa nesses dois campos. Nessa perspectiva, as políticas linguísticas seriam objetos de estudo da sociolinguística da sociedade, embora os estudiosos não tivessem poder para determiná-las.

A sociolinguística brasileira, conforme demonstrado neste texto, ainda pode ser definida como uma teoria da língua. De modo geral, a maior parte das pesquisas consiste em estudos de fenômenos linguísticos com base em corpora constituídos por meio de procedimentos de coleta de dados controlados pelo pesquisador e nos quais o sujeito exerce o papel de mero informante. Uma vez coletados os dados, os pesquisadores elegem os fenômenos que serão estudados e procedem a análises prioritariamente quantitativas. ${ }^{6}$ As amostras de fala são os únicos códigos coletados e,

\footnotetext{
${ }^{6}$ Entre os principais projetos de pesquisa que se enquadram nessa metodologia, estão o Projeto Variação Linguística no Estado da Paraíba (VALPB), o Programa de Estudos sobre o Uso da Língua (PEUL), Rio de Janeiro, Análise Contrastiva de Variedades do
} 
mesmo quando tratam da escrita, estão interessados na transferência de variações da fala para a escrita. A metodologia também não contempla os testes de avaliação subjetiva da variação estilística, aspecto bastante valorizado na metodologia laboviana. Nesse sentido, a sociolinguística brasileira radicaliza o formalismo linguístico e aprofunda o abismo que a separa de uma abordagem social da língua (CAMACHO, 2013).

Diante das limitações da sociolinguística como ciência pura para lidar com questões sociais mais amplas que envolvem a natureza e o funcionamento sociopolítico da linguagem, os projetos reformistas sobre padronização linguística propostos por alguns sociolinguistas aplicados, orientados pelo ideal de transferência dos saberes científicos à vida social, revelam-se não apenas frágeis e inconsistentes, mas, sobretudo, incoerentes com aquilo que se espera de uma teoria social da linguagem. Uma abordagem adequada do problema que envolve a relação entre norma padrão e variação linguística na sociedade não se pode limitar a uma abordagem naturalista da língua. Não é possível negar factualidade social à norma padrão, ao mesmo tempo que não é possível ignorar a legitimidade social das diversas variedades que constituem uma língua.

Calvet (2002) assinala que o fato de a sociolinguística variacionista partir da ideia de que a língua reflete a sociedade foi responsável por fechar a língua nessa definição Diante disso, apresenta-se o problema: "como a língua, uma língua, poderia refletir a sociedade quando ela é plurilíngue?" (p. 106). Esse questionamento leva-o à conclusão de que a noção de comunidade de fala, na metodologia de Labov, é um artifício utilizado para conferir certa unidade ao objeto de estudo. Para Calvet, a saída desse paradoxo é sair da língua e tomar como ponto de partida a realidade social. Esse entendimento amplia radicalmente o escopo da sociolinguística em direção à comunidade social sob seu aspecto linguístico. Por essa razão, Calvet argumenta que não há mais possibilidade de distinção entre sociolinguística e linguística, e ainda menos entre sociolinguística e sociologia da linguagem. Assim sendo, a tarefa do linguista é descrever as mútuas relações entre grupos sociais, falantes, códigos, variedades de códigos e relações dos falantes com esses códigos e situações de comunicação. O autor enumera essas tarefas (CALVET, 2002, p. 108):

Português (VARPORT), Projeto de cooperação internacional Brasil/Portugal, Variação Linguística Urbana no Sul do País (VARSUL), Projeto de Estudo da Norma Linguística Urbana Culta (NURC). 
1. Descrever os códigos em presença (é o que fazem, grosso modo, as diferentes linguísticas), mas levando em conta a dimensão diacrônica, a história desses códigos e das pessoas que os utilizam (o que nem todas as linguísticas fazem);

2. Estruturar a comunidade em função desses códigos, ou seja, descrever os subgrupos de acordo com as línguas que eles falam, com os lugares onde falam, com quem falam, por que lhes falam etc., descrever também as redes de comunicação, os comportamentos, as atitudes...;

3. Descrever as variações no uso dos códigos em função das diversas variáveis sociais (sexo, categorias sociais, idade etc.);

4. Descrever os efeitos dessa coexistência sobre os próprios códigos: empréstimos, interferências etc.;

5. Descrever os efeitos da situação social sobre os códigos: é o problema das relações entre forma e função.

De acordo com Calvet, cada uma dessas tarefas é, ao mesmo tempo, linguística e sociológica, o que exige uma abordagem interdisciplinar em que teorias e métodos da linguística, da sociologia, da linguística antropológica e da etnografia da comunicação se articulam para a compreensão da natureza e do funcionamento social da língua. Calvet e Fasold estão de acordo quanto à concepção da sociolinguística como ciência social, cujas descrições e explicações podem ser aplicadas às políticas linguísticas. A esse respeito, os autores concordam também que apenas o Estado tem o poder e os meios de fazer esses conhecimentos passarem ao estágio do planejamento - da implementação concreta de uma política linguística -, de pôr em prática suas escolhas políticas. A despeito de todas essas considerações, os sociolinguistas aplicados brasileiros têm optado por considerar os resultados das pesquisas empíricas, voltadas, sobretudo, para fins de descrição linguística, como principais argumentos para justificar suas teses acerca da padronização linguística. 


\section{Agradecimento}

Agradeço aos (às) pareceristas pela leitura atenta e cuidadosa do texto, bem como pelas problematizações e sugestões que contribuíram para o amadurecimento das reflexões nele apresentadas. Os equívocos que porventura persistam são de minha inteira responsabilidade.

\section{Referências}

ADORNO, T. W.; HORKHEIMER, M. Dialética do esclarecimento: fragmentos filosóficos. Tradução de Guido Antônio de Almeida. Rio de Janeiro: Zahar Editor, 1985.

BAGNO, M. A norma oculta: língua e poder na sociedade brasileira. São Paulo: Parábola Editorial, 2003.

BAGNO, M. Não é errado falar assim! Em defesa do português brasileiro. São Paulo: Parábola Editorial, 2009.

BAGNO, M. Gramática pra que te quero? Os conhecimentos linguísticos nos livros didáticos de português. Curitiba: Aymará, 2010.

BAGNO, M. Gramática pedagógica do português brasileiro. São Paulo: Parábola Editorial, 2011.

BAKHTIN, M. Estética da criação verbal Tradução de Paulo Bezerra. 4. ed. São Paulo: Martins Fontes, 2003.

BENVENISTE, E. Problemas de linguística geral II. Tradução de Eduardo Guimarães. 2. ed. Campinas, SP: Pontes Editores, 2006.

BASTIDE, R. Antropologia Aplicada. Tradução de Maria Lúcia Pereira e J. Guinsburg. São Paulo: Perspectiva, 2009.

BOURDIEU, P. A economia das trocas linguísticas: o que falar quer dizer. 2. ed. Tradução de Sérgio Miceli et al. São Paulo: Editora da UNESP. 2008.

CALVET, L. J. Sociolinguística: uma introdução crítica. Tradução de Marcos Marcionílio. São Paulo: Parábola Editorial, 2002.

CAMACHO, R. G. Da linguística formal à linguística social. São Paulo: Parábola Editorial, 2013. 
COELHO, I. L. et al. Para conhecer sociolinguística. São Paulo: Contexto, 2015.

CORBEIL, J. C. Elementos de uma teoria da regulação linguística. Tradução de Marcos Bagno. In: BAGNO, M. (Org.). Norma linguística. São Paulo: Edições Loyola, 2001, p. 175-201.

ECKERT, P. Three waves of variation study: the emergence of meaning in the study of sociolinguistic variation. Annual Review of Anthropology, Stanford University Press, v. 41, p. 87-100, June 2012. DOI: https://doi. org/10.1146/annurev-anthro-092611-145828

ECKERT, P.; McCONNELL-GINET, S. Think practically and look locally. Annual Review of Anthropology, Stanford University Press, v. 21, p. 46190, 1992. DOI: https://doi.org/10.1146/annurev.an.21.100192.002333

FARACO, C. A. Norma culta brasileira: desatando alguns nós. São Paulo: Parábola Editorial, 2008.

FASOLD, R. La sociolingüística de la sociedade: introducción a la sociolingüística. Tradução de Margarita España Villasante y Joaquín Mejía Alberdi. Madrid: Visor Libros, 1996.

FOUCAULT, M. Microfísica do poder. Tradução de e Organização de Roberto Machado. Rio de Janeiro: Edições Graal, 1979.

GIDDENS, A. A constituição da sociedade. 3. ed. Tradução de Álvaro Cabral. 3. ed. São Paulo: Editora WMF Martins Fontes, 2009.

HALL, S. O problema da ideologia: o marxismo sem garantias. In: . Da diáspora: identidades e mediações culturais. Tradução de Adelaine La Guardia Resende et al. Editora da UFMG; Brasília: Representação da Unesco no Brasil, 2003. p. 265-293.

HUGHES, J. A filosofia da pesquisa social. Tradução de Heloisa Toller Gomes. Rio de Janeiro: Zahar Editores, 1983.

ILARI, R.; NEVES, M. H. M. (Org.). Gramática do português culto falado no Brasil. v. 2: Classes de palavras e processos de construção. Campinas, SP: Editora da Unicamp, 2008.

JUBRAN, C.C.A.S.; KOCH, I. G. V. (Org.). Gramática do português culto falado no Brasil. v. 1: Construção do texto falado. Campinas: Editora da Unicamp, 2006. 
KATO, M. A.; NASCIMENTO, M. (Org.). Gramática do português culto falado no Brasil. v. 3: A construção da sentença. Campinas: Editora da Unicamp, 2009.

KERBRAT-ORECCHIONI, C. Análise da conversação. Tradução de Carlos Piovezani Filho. São Paulo: Parábola Editorial, 2006.

LABOV, W. The social stratification of English in New York City. Cambridge: Cambridge University Press, 2006. DOI: https://doi. org/10.1017/CBO9780511618208

LABOV, W. Padrões sociolinguísticos. Tradução de Marcos Bagno et al. São Paulo: Parábola Editorial, 2008.

LUCCHESI, D. Língua e sociedade partidas: a polarização sociolinguística no Brasil. São Paulo: Contexto, 2015.

MAINGUENEAU, D. Pragmática para o discurso literário. Tradução de Marina Appenzeller. São Paulo: Martins Fontes, 1996.

MAINGUENEAU, D. Análise de textos de comunicação. 2. ed. Tradução de Cecília Souza-e-Silva e Décio Rocha. São Paulo: Cortez, 2002.

MARTINS, M. A.; VIEIRA, S. R.; TAVARES, M. A. Ensino de português e sociolinguística. São Paulo: Parábola Editorial, 2014.

MATTOS E SILVA, R. V. Contradições no ensino de português: a língua que se fala x a língua que se ensina. 7. ed. São Paulo: Contexto, 2005.

PERINI, M. A. Gramática do português brasileiro. São Paulo: Parábola Editorial, 2010.

PERRENOUD, P. A prática reflexiva no ofício de professor: profissionalização e razão pedagógica. Tradução de Cláudia Schilling. Porto Alegre: Artmed, 2002.

RAJAGOPALAN, K. Política linguística: do que é que se trata, afinal? In: NIKOLAIDES, C. et al. (Org.). Política e políticas linguísticas. Campinas: Pontes Editores, 2013.p. 19-42.

SANTOS, B. S. Um discurso sobre as ciências. 5. ed. São Paulo: Cortez, 2008.

SCHERRE, M. M. P. Doa-se lindos filhotes de poodle: variação linguística, mídia e preconceito. São Paulo: Parábola Editorial, 2005. 
WEINREICH, U.; LABOV, W.; HERZOG, M. I. Fundamentos empíricos para uma teoria da mudança linguística. Tradução de Marcos Bagno. São Paulo: Parábola Editorial, 2006.

ZABALA, A. Enfoque globalizador e pensamento complexo: uma proposta para o currículo escolar. Tradução de Ernani Rosa. Porto Alegre: Artmed, 2002.

ZILlES, A. M. S.; FARACO, C. A. (Org.). Pedagogia da variação linguística: língua, diversidade e ensino. São Paulo: Parábola Editorial, 2015. 